\title{
Water Saving Irrigation Standard of Tomato in Greenhouse
}

\author{
Ki-Cheol Eom, Byung-Kook Lee, Mun-Hwan Koh, Ho-Yong Eom, and Yeun-Kyu Sonn ${ }^{1 *}$ \\ Sejong Institute of Data Analysis (SEIDA), Suwon 443-766, Korea \\ ${ }^{1}$ National Academy of Agricultural Science, RDA, 441-707, Suwon-city, Gyeonggi-do, Korea.
}

(Received: June 3 2013, Accepted: September 2 2013)

The Average daily PET (Potential evapotranspiration), evaluated based on the last 30 years meteorological data and the lysimeter experiment caried out by RDA during 11 years, of 9 regions in Korea for the tomato cultivated in greenhouse, was $3.41 \mathrm{~mm} \mathrm{day}^{-1}$. Two kinds of water saving inigation standard (WSIS), deficit inigation standard (DIS) and partial root-zone drying inigation standard (PRDIS) that include the irrigation interval and the amount of irigation water according to the region, soil texture and growing stage, were established. According to the DIS and PRDIS, the cultivator can save water up to $29.2 \%$ and $53.7 \%$, respectively, for tomato cultivation in greenhouse compared to the full irigation standard (FIS) which established in 1999. WSIS can be used easily by the cultivator without complicate procedures such as soil sampling and measurement of soil water status by expensive sensors. But the cultivator should care about inigation method such as PRDI (partial root-zone drying inigation) without yield decrease.

Key words: Irrigation Standard, Full Irrigation, Water Saving Irrigation, Deficit Irrigation, Partial Root-zone Drying Irrigation

Amount of total imigation water by full inigation stard (FIS), deficit irigation standard (DIS) and partial root-zone drying inigation standard (PRDIS) of tomato in greenhouse.

\begin{tabular}{lcccccccccc}
\hline \hline Area & Suwon & Gangneung & Buyeo & Jecheon & Mokpo & Jeonju & Milyang & Yeongju & Jeju & Mean \\
\hline FIS & 387.7 & 545.3 & 377.8 & 363.4 & 409.4 & 389.4 & 389.5 & 399.7 & 380.6 & 404.8 \\
DIS & 280.7 & 271.4 & 268.9 & 256.6 & 337.0 & 277.7 & 284.3 & 296.6 & 308.2 & 286.8 \\
PRDIS & 183.2 & 181.2 & 179.7 & 176.5 & 223.9 & 182.4 & 183.9 & 189.1 & 187.0 & 187.4 \\
\hline
\end{tabular}




\section{Introduction}

전 세계적으로 산업, 농업, 인간, 생태계 등 여러 분야에 서의 물 사용에 의해 잠재적인 물 보존량이 위협을 받고 있 으며, 그 중 관개농업은 수자원의 가장 큰 소비자 중 하나이 다 (Ward and Trimble, 2004). 기후조건에 영향을 가장 크 게 받는 농업은 최근 지속된 기상이변으로 정기적인 가뭄에 직면하고 있는 국가가 늘고 있는 실정임에도 불구하고 작물 생산량과 수요가 늘고 있어 증가하는 생산량을 유지하면서 물이용 효율을 증가시킬 수 있는 물 절약형 관리 기준이 요 구되고 있다. 작물의 물 관리 기준은 크게 보아 3가지 요인 에 따라 결정된다. 첫째, 기상상태에 따른 대기의 증발요구 량, 둘째, 작물체를 통한 물 이동성, 그리고 셋째, 작물에게 물을 공급하는 토양수분 변화량이다.

첫째 요인인 대기의 증발요구량을 구명하기 위해서는 유 효강우량, Pan 증발량 (대형 또는 소형), 기온, 풍속, 일사 량, 상대습도 등 대기의 증발요구량과 관련성이 높은 여러 기후 인자를 고려해야 한다. 우선 대기로부터 토양 수분을 공급해 주는 기후, 즉 강수량을 우선 살펴보면 최근 30 년간 (1981 2010) 우리나라의 연평균 강수량은 $1,308 \mathrm{~mm}$ 이며, 계절적으로 보면 연강수량의 50 60\%가 7월 8월 사이에 집 중되어 있어 밭작물 재배에 효과적이지 못한 실정이다. 우 리나라의 권역별 강수량은 중부지역이 $1,100 ~ 1,400 \mathrm{~mm}$ 이 고, 남부지역은 $1,000 ~ 1,800 \mathrm{~mm}$ 이며, 제주도는 1,450 $1,850 \mathrm{~mm}$ 로 매우 큰 차이를 보이고 있다(KMA, 2008). 다음 으로 토양으로부터의 증발 또는 작물의 증산작용에 의하여 대기로 물을 보내는 양은 대기의 증발요구량에 의해 일차적 인 지배를 받으며 우리는 그 양을 잠재증발산량 (PET: Potential evapotranspiration)으로 지표로 삼는다. 지금까 지 세계적으로 잠재증발산량 추정을 위해 Penman법 (1948, 1956), 수정 Penman법, Blaney-criddle법 (1962), Radiation법, Pan evaporation법, Jensen-Haise법 (1963, 1974), PenmanMonteith (FAO PM)등 다양한 모형이 제시되고 사용되어 왔으며, 우리나라에서는 임 (1988)이 국내 최초로 4가지의 서로 다른 증발산량 모형을 비교 분석하여 우리나라에 적합 한 잠재증발산량 추정모형을 개발하였다. 둘째 요인인 작물 체를 통한 물 이동성은 주어진 기상조건과 토양 조건에서도 작물별 및 작물의 생육시기별 달라지게 되며, 우리는 그 양 을 작물계수 (Kc: Crop coefficient)로 정의되는 양을 지표 로 삼는다. 그러나 작물별 및 생육시기별 작물계수를 구명 하기 위해서는 포장조건에서 Lysimeter 시설을 이용하여 장기간 실측하여야 하므로 연구자마다 연구할 때 마다 작물 계수를 구명한다는 것은 불가능하기 때문에, 물 관련 연구 자들은 국제기구 (FAO 등) 또는 자국의 국가연구기관에서 수행한 연구결과를 활용하는 수 밖에 없다. 셋째 요인인 토 양수분과 관련한 사항이 가장 어렵고 복잡하며, 또한 토양
마다 구명되어야 할 물 관련 특성, 즉 토양의 물 보유능, 물 전달능 (Hydraulic conductivity), 물 이동속도, 토양수분 함량과 토양수분 Potential 과의 관련성, 시기별 및 토양깊 이별 토양수분 변화량 등 그 내용이 너무 많아서, 작물 재배 과정에서 이 모든 특성을 구명하여 물 관리를 하는 것은 불 가능하다.

또한, 대부분의 밭작물 재배 농가에서는 경험에 의해 관 개를 하고 있어 적절한 물관리가 이루어지지 않고 있는 실 정이다. 적절한 물관리를 위해서는 기상조건을 고려한 지역 별 기상조건, 토양 종류별 특성, 작물 및 생육단계별 작물의 물 이동 특성 등 각각의 조건에 맞는 물 관리 기준 설정이 필요하다. 현재 전 세계적으로 사용하고 있는 관개기준은 완전관개 기준 (FIS: Full Irrigation Standard)과 물 절약형 관개기준 (WSIS: Water Saving Irrigation Standard)으로 구분할 수 있으며, WSIS는 다시 부족 관개기준 (DIS: Deficit Irrigation Standard)과 부분건조 관개기준 (PRDIS: Partial Root-zone Drying Irrigation Standard)으로 구분된다 (Sepaskhah et al., 2010).

농민들의 물 관리 어려움을 해결하기 위해 농촌진흥청에 서는 지역별·토양 종류별·작물 및 생육단계별로 관개기준인 밭작물 물관리 지침서 (Eom et al., 1999)를 보급하였으나, 이는 최대 수량(收量) 확보를 위한 최대 관개를 그 기준으로 하고 있다. 즉, 관개기준의 구분으로 볼 때 완전 관개기준 (FIS)에 해당된다. 그러나 이 기준은 물 소모량이 너무 많아 물 부족을 겪고 있는 작금의 우리나라에서는 적용하는데 현 실적인 한계가 있다.

따라서, 본 연구는 수량 감소가 거의 없는 수준의 최소 관개 개념 하에, 시설재배 토마토의 물 절약형 관개 기준 즉, 부족 관개기준 (DIS)과 부분건조 관개기준 (PRDIS)을 마련하고 동시에 상기한 최대관개 기준과 비교하여 어느 정 도 물 절약이 가능한지 구명코자 하였다.

\section{Materials and Methods}

본 연구의 대상지역은 우리나라 9 개도에서 각 1 개 지역씩 총 9 개 지역을 선정 (경기 수원, 강원 강릉, 충남 부여, 충북 제천, 전남 목포, 전북 전주, 경남 밀양, 경북 영주, 제주 북 제주) 하여 지역별 관개기준을 설정하였다.

토마토의 노지재배 조건에서의 잠재증발산량 (PETOF : Potential Evapotranspiration in the Open Field)의 산정은 대형 pan 증발량 (Eo)값을 이용하여 개발된 추정모형 (임정 남, 1987)인 식 (1)에 근거하여 산출하였다.

$\mathrm{PETOF}=0.712+0.705 \mathrm{EO}$

그러나, 근래로 오면서 기상관측소에서 측정하는 $\mathrm{Pan}$ 증 
발량은 대형 $\mathrm{Pan}$ 증발량이 아니고 소형 $\mathrm{Pan}$ 증발량이다. 따라서 지역별 과거의 기상 자료를 이용하여 대형 Pan 증발 량과 소형 Pan 증발량 (Es)과의 관계식을 식 (2)에 따라 구 명하여 식 (1)에 적용시켰다.

$$
\text { Eo }=a+b \text { Es }
$$

또한, 시설재배 조건에서의 잠재증발산량 (PETGH : Potential Evapotranspiration in Green House)은 노지재배 조건의 잠재증발산량에 대한 상대계수 (r)값 (ASTI, 1986)을 이용하 여 식 (3)와 같이 산출하였다.

이때 $\mathrm{r}$ 값은 토마토 재배 기간인 5 월 6 월에 각각 1.13 과 1.08 을 7 8월은 1.12 를 적용하였다.

$$
\text { PETGH }=\text { PETOF } \times r
$$

시설재배 토마토의 생육시기별 작물계수 (Kc: Crop coefficient)는 시설재배 토마토의 생육시기별 해당 기상조 건에 따른 토양수분 부족이 전혀 없는 조건에서의 작물별 최대증발산량 (MET : Maximum Evapotranspiration)를 이 용하여 식 (4)에 의하여 산출하였다.

$$
\mathrm{Kc}=(\mathrm{MET} / \mathrm{PET})
$$

본 연구에서, 시설재배 토마토에 대한 잠재증발산량 (PETGH) 는 근래 30년간 (1999 2008) 지역별 순별 기상자료 (KMA, 2008)의 소형 pan 증발량 (Es)값을 이용하여 식 (1)과 식 (2) 에 근거하여 $\mathrm{PETOF}$ 를 산출한 후, 농촌진흥청 농업과학기술 원 (1986)의 결과에 따라 $\mathrm{r}$ 값을 적용 식 (3)을 산출하였다. 시설 토마토의 작물계수는 농촌진흥청 농업과학기술원 시 험포장 내의 Lysimeter에서 11년간 ('81-'91) 잠재증발산량 (PET) 및 최대증발산량 (MET)을 실측한 결과에 따라 생육 시기별 작물계수를 구하였다.

토마토의 Lysimeter 재배는 5 월 8일 정식하여 무 피복 상 태에서 8월 30일 수확하였다

또한, 토양의 특성이 다른 실제 재배조건에서 작물의 실 제 증발산량 (AET: Actual Evapotranspiration)은 토양수분 조건에 영향을 받으며, 그 정도는 식 (5)와 같은 토양 수분 계수 (Ksw: Soil Water Coefficient)를 이용하여, 식 (6)과 같이 실제 증발산량을 산출한다.

$\mathrm{Ksw}=(\mathrm{AET} / \mathrm{MET})$

$\mathrm{AET}=\mathrm{PET} \times \mathrm{Kc} \times \mathrm{KsW}$

본 연구에서 주어진 기간 동안 누적증발산량은 근권 내

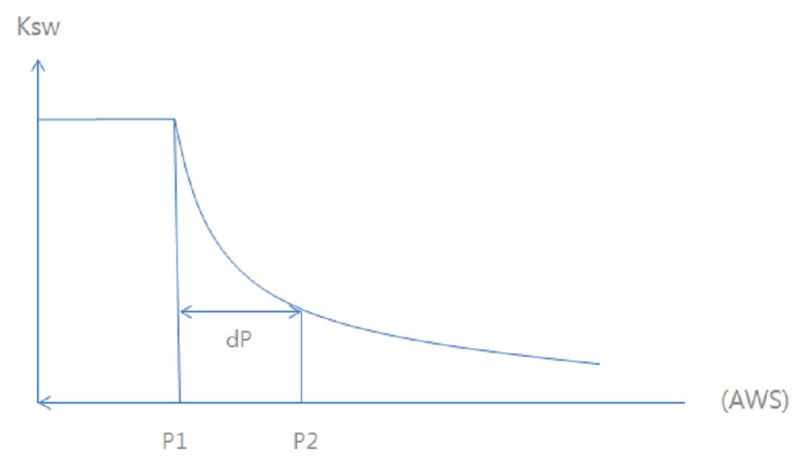

Fig. 1. Theory of the relationship between available water storage (AWS) and soil water coefficient (Ksw).

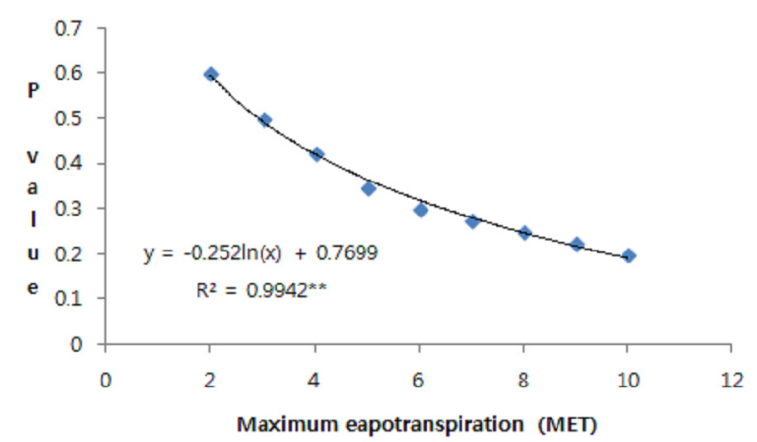

Fig. 2. Soil water depletion fraction $(P)$ as a function of MET.

유효수분보유량 (AWS: Available Water Storage)에 대한 근권 수분보유량의 비율인 $\mathrm{P}$ 값을 산정하여 산출할 수 있으 며 (FAO, 1971), P값은 AWS 및 토양수분장력의 함수로서, Fig. 1과 같은 이론에 근거를 두고, 2개의 임계점 (Soil Water Depletion Fraction)인 $\mathrm{P} 1$ 과 $\mathrm{P} 2$ 의 차이 값인 $\mathrm{dP}$ 값을 설정 함에 있어, $\mathrm{P} 1$ 은 관개목표 토양수분장력인 $15 \mathrm{kPa}$ 때의 $\mathrm{P}$ 값 으로 설정한 후, $\mathrm{P} 2$ 는 부족관개기준 (DIS)의 경우 관개시점 토양수분 장력인 $30 \mathrm{kPa}$ 때의 $\mathrm{P}$ 값으로 산정하였으며, 부분 건조 관개기준 (PRDIS)의 경우 $\mathrm{MET}$ 에 대한 함수식의 연구 결과 (FAO, 1971)를 이용하여, 같은 포장에서 작물별 토양 수분 potential 영향시험 결과 (Eom et al., 1983)에 근거하 여 시설토마토에 맞는 함수식 (Fig. 2)을 구명하여 산정하였다. 따라서 누적증발산량은 Fig. 1 의 dP에 해당되는 토양수 분 보유량의 변화량이 된다.

토성별 근권 내 유효수분보유량 (AWS)은 토성별로 측정 한 포장용수량 (Fc: Field capacity)과 위조계수 (Wp: Wilting point)값을 이용하여 식 (7)과 같이 구하였다.

$$
\mathrm{AWS}=\mathrm{FC}-\mathrm{WP}
$$

토성별 $\mathrm{FC}$ 와 $\mathrm{WP}$ 값은, 3개 토성에 대하여 사양토 36 점, 미사질양토 8점, 양토 33점, 총 77점의 토양시료를 채취하 여 pressure plate 법 (Klute, 1986)으로 측정한 토성별 평 
Table 2. PETGHavg for the tomato cultivated in greenhouse at different area according to growing season. (unit : $\mathrm{mm} \mathrm{day}^{-1}$ )

\begin{tabular}{|c|c|c|c|c|c|c|c|c|c|c|c|}
\hline Season & Area & Suwon & Gangneung & Buyeo & Jecheon & Mokpo & Jeonju & Milyang & Yeongju & Jeju & Average \\
\hline \multirow{2}{*}{ May } & $\mathrm{M}$ & 3.45 & 3.85 & 3.33 & 3.44 & 3.21 & 3.42 & 3.54 & 4.19 & 3.41 & 3.54 \\
\hline & $\mathrm{L}$ & 3.90 & 4.15 & 3.93 & 3.84 & 3.63 & 3.94 & 4.03 & 4.60 & 3.71 & 3.97 \\
\hline \multirow{3}{*}{ Jun. } & $\mathrm{F}$ & 3.63 & 3.66 & 3.53 & 3.54 & 3.35 & 3.75 & 3.70 & 4.27 & 3.46 & 3.66 \\
\hline & M & 3.80 & 3.37 & 3.47 & 3.46 & 3.16 & 3.64 & 3.47 & 3.85 & 3.27 & 3.50 \\
\hline & $\mathrm{L}$ & 3.17 & 2.90 & 2.98 & 3.12 & 2.42 & 2.72 & 2.90 & 3.35 & 2.82 & 2.93 \\
\hline \multirow{3}{*}{ Jul. } & $\mathrm{F}$ & 3.16 & 3.08 & 3.02 & 2.92 & 2.49 & 2.82 & 3.22 & 3.28 & 3.44 & 3.05 \\
\hline & M & 2.88 & 2.97 & 2.57 & 2.41 & 2.74 & 2.66 & 2.95 & 2.88 & 3.81 & 2.87 \\
\hline & $\mathrm{L}$ & 3.30 & 3.26 & 3.20 & 2.71 & 3.67 & 3.59 & 3.59 & 3.22 & 4.43 & 3.44 \\
\hline \multirow{2}{*}{ Aus. } & $\mathrm{F}$ & 3.61 & 3.34 & 3.78 & 3.42 & 3.96 & 3.85 & 3.75 & 3.92 & 4.41 & 3.78 \\
\hline & $\mathrm{M}$ & 3.50 & 2.89 & 3.16 & 3.10 & 3.49 & 3.29 & 3.38 & 3.33 & 3.65 & 3.31 \\
\hline \multicolumn{2}{|c|}{ Average } & 3.44 & 3.35 & 3.30 & 3.20 & 3.21 & 3.37 & 3.45 & 3.69 & 3.64 & 3.41 \\
\hline
\end{tabular}

\section{균치 값을 적용하였다.}

1 회 관개량 (A·I: Amount of Irrigation)은 식 (8)과 같이 산정하였다.

$$
[\mathrm{A} \cdot \mathrm{I}]=\mathrm{P} \cdot \mathrm{AWS}=\int_{t 1}^{t 2}(\mathrm{AET}) \mathrm{dt}
$$

또한, 적정관개간격 (I·I : Irrigation Interval)은 식 (9)와 같이 산정하였다.

$$
[\mathrm{I} \cdot \mathrm{I}]=[\mathrm{A} \cdot \mathrm{I}] /\left[\left(\int_{t 1}^{t 2}(\mathrm{AET}) \mathrm{dt}\right) /(\mathrm{t} 2-\mathrm{t} 1)\right]
$$

\section{Results and Discussion}

연구 결과 및 고찰 지역별 과거의 기상 자료를 이용하 여 대형 $\mathrm{Pan}$ 증발량 $(\mathrm{Eo})$ 과 소형 $\mathrm{Pan}$ 증발량 $(\mathrm{Es})$ 과의 관계 식을 직선회귀식으로 구한 결과는 Table 1과 같으며 전 지 역 모두 그 상관계수가 $1 \%$ 유의수준에서 유의성이 인정되었 다. 이 결과를 이용하여 우리나라 9 개 지역에 대하여 시설 재배 토마토 주 재배시기인 5월 8월까지의 근래 30년간 (1999 2008) 기상자료와 식 $(1,2,3)$ 에 의하여 산정된 순 별 일 평균 시설 내 잠재증발산량 (PETGHavg)은 Table 2와 같다. 최소 제천 (7월 중순)의 $2.41 \mathrm{~mm} \mathrm{day}^{-1}$ 로부터 최대 여주 (5월 중순)의 $4.60 \mathrm{~mm}^{-1}{ }^{-1}$ 범위였으며, 9 개 지역에 대한 전체 평균값은 $3.41 \mathrm{~mm} \mathrm{day}^{-1}$ 이었다.

식 (4)에 의하여 산정되는 시설재배 토마토의 생육시기별 작물계수는, 토마토를 정식한 이후 생육초기 $(\mathrm{G}-1: 5 / 10$ $5 / 31$ )에는 0.62 , 생육중기 (G-2: 6/1 6/30)에는 1.06, 생육 후기 (G-3: 7/1 7/31)에는 1.27, 생육후기 $(G-4: 8 / 1 \sim$ 8/20)에는 1.25 를 적용하였다.
Table 1. The coefficient $(a, b)$ and coefficient determination $\left(R^{2}\right)$ of the regression between Eo and Es in equation (2) according to the region.

\begin{tabular}{lccc}
\hline \hline Region & $\mathrm{a}$ & $\mathrm{b}$ & $\mathrm{R}^{2}$ \\
\hline Suwon & 0.7417 & -0.1301 & $0.911^{* *}$ \\
Gangneung & 0.7316 & -0.0649 & $0.924^{* *}$ \\
Buyeo & 0.7902 & -0.3951 & $0.942^{* *}$ \\
Jecheon & 0.7521 & -0.1652 & $0.928^{* *}$ \\
Mokpo & 0.7698 & -0.2461 & $0.952^{* *}$ \\
Jeonju & 0.7427 & -0.1052 & $0.921^{* *}$ \\
Milyang & 0.7819 & -0.2537 & $0.890^{* *}$ \\
Yeongju & 0.7528 & -0.1959 & $0.909^{* *}$ \\
Jeju & 0.7044 & -0.0505 & $0.956^{* *}$ \\
\hline
\end{tabular}

$*$ Eo $=a+b$ Es

Table 3. Available Water Storage (AWS) according to soil texture. (v/v. \%)

\begin{tabular}{cccc}
\hline \hline & SL & SiL & L \\
\hline FC $^{\dagger}$ & 22.3 & 35.1 & 29.4 \\
WP & 6.3 & 10.4 & 8.7 \\
AWS & 16.0 & 24.7 & 20.7 \\
\hline
\end{tabular}

${ }^{\dagger}$ FC: Field Capacity, WP: Wilting Point, AWS: Available Water Storage

식 (7)에 의하여 산정 한 토성별 유효토양수분보유량 (AWS)은 Table 3 과 같이 사양토의 $16.0 \% \mathrm{v} / \mathrm{v}$ 에서 미사질 양토 $24.7 \% \mathrm{v} / \mathrm{v}$ 범위이었다.

최대증발산량 (MET)의 함수로 구한 임계점 P값 (Fig. 2) 은 식 (10)과 같다.

$$
\mathrm{p}=-0.252 \ln (\mathrm{MET})+0.7699
$$


Table 4. Deficit inigation standard (DIS) for tomato in greenhouse.

\begin{tabular}{|c|c|c|c|c|c|c|}
\hline area & texture & Irrigation & $\mathrm{CG}^{\mathrm{G}} \mathbf{1}^{\dagger}$ & G-2 & G-3 & G-4 \\
\hline \multirow{6}{*}{ Suwon } & \multirow{2}{*}{$\mathrm{SL}^{\dagger \dagger}$} & $A \cdot I^{i \dagger \dagger}$ & 13.2 & 13.2 & 13.2 & 13.2 \\
\hline & & $\mathrm{I} \cdot \mathrm{I}$ & 7.1 & 5.9 & 4.1 & 3.6 \\
\hline & \multirow{2}{*}{$\mathrm{L}$} & $A \cdot I$ & 17.1 & 17.1 & 17.1 & 17.1 \\
\hline & & $\mathrm{I} \cdot \mathrm{I}$ & 9.3 & 7.7 & 5.3 & 4.7 \\
\hline & \multirow{2}{*}{$\mathrm{SiL}$} & $A \cdot I$ & 17.6 & 17.6 & 17.6 & 17.6 \\
\hline & & $\mathrm{I} \cdot \mathrm{I}$ & 9.5 & 7.8 & 5.4 & 4.8 \\
\hline \multirow{6}{*}{ Gangneung } & \multirow{2}{*}{ SL } & $A \cdot I$ & 13.2 & 13.2 & 13.2 & 13.2 \\
\hline & & $\mathrm{I} \cdot \mathrm{I}$ & 6.5 & 6.2 & 4.1 & 4.1 \\
\hline & \multirow{2}{*}{$\mathrm{L}$} & $A \cdot I$ & 17.1 & 17.1 & 17.1 & 17.1 \\
\hline & & $\mathrm{I} \cdot \mathrm{I}$ & 8.5 & 8.1 & 5.3 & 5.4 \\
\hline & \multirow{2}{*}{$\mathrm{SiL}$} & $A \cdot I$ & 17.6 & 17.6 & 17.6 & 17.6 \\
\hline & & $\mathrm{I} \cdot \mathrm{I}$ & 8.7 & 8.3 & 5.4 & 5.5 \\
\hline \multirow{6}{*}{ Buyeo } & \multirow{2}{*}{ SL } & $A \cdot I$ & 13.2 & 13.2 & 13.2 & 13.2 \\
\hline & & $\mathrm{I} \cdot \mathrm{I}$ & 7.2 & 6.3 & 4.3 & 3.7 \\
\hline & \multirow{2}{*}{$\mathrm{L}$} & $A \cdot I$ & 17.1 & 17.1 & 17.1 & 17.1 \\
\hline & & $\mathrm{I} \cdot \mathrm{I}$ & 9.4 & 8.2 & 5.6 & 4.9 \\
\hline & \multirow{2}{*}{$\mathrm{SiL}$} & $A \cdot I$ & 17.6 & 17.6 & 17.6 & 17.6 \\
\hline & & $\mathrm{I} \cdot \mathrm{I}$ & 9.6 & 8.3 & 5.8 & 5.0 \\
\hline \multirow{6}{*}{ Jecheon } & \multirow{2}{*}{ SL } & $A \cdot I$ & 13.2 & 13.2 & 13.2 & 13.2 \\
\hline & & $\mathrm{I} \cdot \mathrm{I}$ & 7.2 & 6.2 & 4.7 & 4.0 \\
\hline & \multirow{2}{*}{$\mathrm{L}$} & $A \cdot I$ & 17.1 & 17.1 & 17.1 & 17.1 \\
\hline & & $\mathrm{I} \cdot \mathrm{I}$ & 9.3 & 8.1 & 6.2 & 5.2 \\
\hline & \multirow{2}{*}{$\mathrm{SiL}$} & $A \cdot I$ & 17.6 & 17.6 & 17.6 & 17.6 \\
\hline & & $\mathrm{I} \cdot \mathrm{I}$ & 9.5 & 8.3 & 6.3 & 5.3 \\
\hline \multirow{6}{*}{ Mokpo } & \multirow{2}{*}{ SL } & $A \cdot I$ & 13.2 & 13.2 & 13.2 & 13.2 \\
\hline & & $\mathrm{I} \cdot \mathrm{I}$ & 7.6 & 6.8 & 4.3 & 3.5 \\
\hline & \multirow{2}{*}{$\mathrm{L}$} & $A \cdot I$ & 17.1 & 17.1 & 17.1 & 17.1 \\
\hline & & $\mathrm{I} \cdot \mathrm{I}$ & 10.0 & 8.8 & 5.5 & 4.5 \\
\hline & \multirow{2}{*}{$\mathrm{SiL}$} & $A \cdot I$ & 17.6 & 17.6 & 17.6 & 17.6 \\
\hline & & $\mathrm{I} \cdot \mathrm{I}$ & 10.2 & 9.0 & 5.7 & 4.6 \\
\hline \multirow{6}{*}{ Jeonju } & $\mathrm{SI}$ & $A \cdot I$ & 13.2 & 13.2 & 13.2 & 13.2 \\
\hline & $\mathrm{SL}$ & $\mathrm{I} \cdot \mathrm{I}$ & 7.1 & 6.0 & 4.2 & 3.6 \\
\hline & $\mathrm{I}$ & $A \cdot I$ & 17.1 & 17.1 & 17.1 & 17.1 \\
\hline & $\mathrm{L}$ & $\mathrm{I} \cdot \mathrm{I}$ & 9.3 & 7.8 & 5.5 & 4.7 \\
\hline & $\mathrm{SiI}$ & $A \cdot I$ & 17.6 & 17.6 & 17.6 & 17.6 \\
\hline & SiL & $\mathrm{I} \cdot \mathrm{I}$ & 9.5 & 7.9 & 5.6 & 4.8 \\
\hline & & $A \cdot I$ & 13.2 & 13.2 & 13.2 & 13.2 \\
\hline & SL & $\mathrm{I} \cdot \mathrm{I}$ & 6.9 & 6.1 & 3.9 & 3.6 \\
\hline ri 1 & $T$ & $A \cdot I$ & 17.1 & 17.1 & 17.1 & 17.1 \\
\hline M11lyang & L & $\mathrm{I} \cdot \mathrm{I}$ & 9.0 & 8.0 & 5.1 & 4.7 \\
\hline & C. & $A \cdot I$ & 17.6 & 17.6 & 17.6 & 17.6 \\
\hline & SiL & $\mathrm{I} \cdot \mathrm{I}$ & 9.2 & 8.2 & 5.2 & 4.8 \\
\hline & SI & $A \cdot I$ & 13.2 & 13.2 & 13.2 & 13.2 \\
\hline & SL & $\mathrm{I} \cdot \mathrm{I}$ & 5.9 & 5.4 & 4.1 & 3.6 \\
\hline & & $A \cdot I$ & 17.1 & 17.1 & 17.1 & 17.1 \\
\hline Yeongju & $\mathrm{L}$ & $\mathrm{I} \cdot \mathrm{I}$ & 7.7 & 7.0 & 5.3 & 4.6 \\
\hline & $\mathrm{SiI}$ & $A \cdot I$ & 17.6 & 17.6 & 17.6 & 17.6 \\
\hline & SiL & $\mathrm{I} \cdot \mathrm{I}$ & 7.9 & 7.2 & 5.4 & 4.7 \\
\hline
\end{tabular}


Table 4. (Continued)

\begin{tabular}{lcccrrr}
\hline \hline area & texture & Irrigation & G-1 & G-2 & G-3 & G-4 \\
\hline & \multirow{2}{*}{$\mathrm{SL}$} & $\mathrm{A} \cdot \mathrm{I}$ & 13.2 & 13.2 & 13.2 & 13.2 \\
& & $\mathrm{I} \cdot \mathrm{I}$ & 7.4 & 6.5 & 3.3 & 3.2 \\
\cline { 2 - 7 } Jeju & $\mathrm{A} \cdot \mathrm{I}$ & 17.1 & 17.1 & 17.1 & 17.1 \\
& $\mathrm{~L}$ & $\mathrm{I} \cdot \mathrm{I}$ & 9.6 & 8.5 & 4.2 & 4.2 \\
\cline { 2 - 7 } & $\mathrm{A} \cdot \mathrm{I}$ & 17.6 & 17.6 & 17.6 & 17.6 \\
& $\mathrm{SiL}$ & $\mathrm{I} \cdot \mathrm{I}$ & 9.8 & 8.7 & 4.3 & 4.3 \\
\hline
\end{tabular}

${ }^{\dagger} \mathrm{A} \cdot \mathrm{I}=$ Amount of Irrigation $(\mathrm{mm}), \mathrm{I} \cdot \mathrm{I}=$ Irrigation Interval (days)

${ }^{\dagger}$ Soil Texture: SL $=$ Sandy Loam, L $=$ Loam, SiL $=$ Silt Loam

${ }^{\dagger \dagger}$ Growth Stage: G-1 = Growth Stage-1 (5/10 5/31), G-2 = Growth Stage-2 (6/1 6/30), G-3 = Growth Stage-3 (7/1 7/31), G-4 = Growth Stage-4 (8/1 8/20)

Table 5. Partial root-zone drying inigation standard (PRDIS) for tomato in greenhouse.

\begin{tabular}{|c|c|c|c|c|c|c|}
\hline $\begin{array}{c}\text { area } \\
\text { na }\end{array}$ & texture & Irrigation & $\overline{\mathrm{G}-1^{\dagger}}$ & 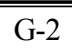 & G-3 & 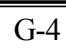 \\
\hline \multirow{6}{*}{ Suwon } & \multirow{2}{*}{$\mathrm{SL}^{\dagger \dagger}$} & $\mathrm{A} \cdot \mathrm{I}^{\dagger \dagger \dagger}$ & 10.7 & 12.0 & 14.5 & 15.3 \\
\hline & & $\mathrm{I} \cdot \mathrm{I}$ & 7.3 & 7.4 & 7.5 & 7.6 \\
\hline & \multirow{2}{*}{$\mathrm{L}$} & $A \cdot I$ & 12.8 & 14.3 & 17.4 & 18.4 \\
\hline & & $\mathrm{I} \cdot \mathrm{I}$ & 8.5 & 8.6 & 8.8 & 8.9 \\
\hline & \multirow{2}{*}{$\mathrm{SiL}$} & $A \cdot I$ & 14.4 & 16.2 & 19.6 & 20.7 \\
\hline & & $\mathrm{I} \cdot \mathrm{I}$ & 9.8 & 9.9 & 10.1 & 10.2 \\
\hline \multirow{6}{*}{ Gangneung } & \multirow{2}{*}{ SL } & $A \cdot I$ & 11.3 & 11.6 & 14.5 & 14.4 \\
\hline & & $\mathrm{I} \cdot \mathrm{I}$ & 7.3 & 7.3 & 7.5 & 7.5 \\
\hline & \multirow{2}{*}{$\mathrm{L}$} & $A \cdot I$ & 13.5 & 13.9 & 17.4 & 17.3 \\
\hline & & $\mathrm{I} \cdot \mathrm{I}$ & 8.5 & 8.6 & 8.8 & 8.8 \\
\hline & \multirow{2}{*}{$\mathrm{SiL}$} & $A \cdot I$ & 15.2 & 15.6 & 19.6 & 19.4 \\
\hline & & $\mathrm{I} \cdot \mathrm{I}$ & 9.9 & 9.9 & 10.1 & 10.1 \\
\hline \multirow{6}{*}{ Buyeo } & \multirow{2}{*}{ SL } & $A \cdot I$ & 10.6 & 116 & 14.1 & 15.1 \\
\hline & & $\mathrm{I} \cdot \mathrm{I}$ & 7.3 & 7.3 & 7.5 & 7.6 \\
\hline & \multirow{2}{*}{$\mathrm{L}$} & $A \cdot I$ & 12.7 & 13.8 & 16.9 & 18.2 \\
\hline & & $\mathrm{I} \cdot \mathrm{I}$ & 8.5 & 8.6 & 8.8 & 8.9 \\
\hline & \multirow{2}{*}{$\mathrm{SiL}$} & $A \cdot I$ & 14.3 & 15.6 & 19.0 & 20.4 \\
\hline & & $\mathrm{I} \cdot \mathrm{I}$ & 9.8 & 9.9 & 10.1 & 10.2 \\
\hline \multirow{6}{*}{ Jecheon } & \multirow{2}{*}{ SL } & $A \cdot I$ & 10.6 & 11.6 & 13.5 & 14.7 \\
\hline & & $\mathrm{I} \cdot \mathrm{I}$ & 7.3 & 7.3 & 7.4 & 7.5 \\
\hline & \multirow{2}{*}{$\mathrm{L}$} & $A \cdot I$ & 12.7 & 13.9 & 16.2 & 17.7 \\
\hline & & $\mathrm{I} \cdot \mathrm{I}$ & 8.5 & 8.6 & 8.7 & 8.8 \\
\hline & \multirow{2}{*}{$\mathrm{SiL}$} & $A \cdot I$ & 14.4 & 15.6 & 18.2 & 19.9 \\
\hline & & $\mathrm{I} \cdot \mathrm{I}$ & 9.8 & 9.9 & 10.1 & 10.2 \\
\hline \multirow{6}{*}{ Mokpo } & \multirow{2}{*}{ SL } & $A \cdot I$ & 10.2 & 11.0 & 14.2 & 15.6 \\
\hline & & $\mathrm{I} \cdot \mathrm{I}$ & 7.2 & 7.3 & 7.5 & 7.6 \\
\hline & \multirow{2}{*}{$\mathrm{L}$} & $A \cdot I$ & 12.2 & 13.2 & 17.1 & 18.8 \\
\hline & & $\mathrm{I} \cdot \mathrm{I}$ & 8.4 & 8.5 & 8.8 & 8.9 \\
\hline & \multirow{2}{*}{$\mathrm{SiL}$} & $A \cdot I$ & 13.8 & 14.9 & 19.2 & 21.1 \\
\hline & & $\mathrm{I} \cdot \mathrm{I}$ & 9.7 & 9.8 & 10.1 & 10.3 \\
\hline
\end{tabular}


Table 5. (Continued)

\begin{tabular}{|c|c|c|c|c|c|c|}
\hline area & texture & Irrigation & G-1 & G-2 & G-3 & G-4 \\
\hline \multirow{6}{*}{ Jeonju } & \multirow{2}{*}{ SL } & $A \cdot I$ & 10.7 & 11.9 & 14.3 & 15.3 \\
\hline & & $\mathrm{I} \cdot \mathrm{I}$ & 7.3 & 7.4 & 7.5 & 7.6 \\
\hline & \multirow{2}{*}{$\mathrm{L}$} & $A \cdot I$ & 12.8 & 14.3 & 17.2 & 19.4 \\
\hline & & $\mathrm{I} \cdot \mathrm{I}$ & 8.5 & 8.6 & 8.8 & 8.9 \\
\hline & \multirow{2}{*}{$\mathrm{SiL}$} & $A \cdot I$ & 14.4 & 16.1 & 19.4 & 20.7 \\
\hline & & $\mathrm{I} \cdot \mathrm{I}$ & 9.8 & 9.9 & 10.1 & 10.2 \\
\hline \multirow{6}{*}{ Milyang } & \multirow{2}{*}{ SL } & $A \cdot I$ & 10.9 & 11.7 & 14.8 & 15.3 \\
\hline & & $\mathrm{I} \cdot \mathrm{I}$ & 7.3 & 7.3 & 7.5 & 7.6 \\
\hline & \multirow{2}{*}{$\mathrm{L}$} & $A \cdot I$ & 13.0 & 14.0 & 17.8 & 18.4 \\
\hline & & $\mathrm{I} \cdot \mathrm{I}$ & 8.5 & 8.6 & 8.8 & 8.9 \\
\hline & \multirow{2}{*}{$\mathrm{SiL}$} & $A \cdot I$ & 14.7 & 15.8 & 20.0 & 20.7 \\
\hline & & $\mathrm{I} \cdot \mathrm{I}$ & 9.8 & 9.9 & 10.2 & 10.2 \\
\hline \multirow{6}{*}{ Yeongju } & \multirow{2}{*}{ SL } & $A \cdot I$ & 11.9 & 12.6 & 14.5 & 15.4 \\
\hline & & $\mathrm{I} \cdot \mathrm{I}$ & 7.4 & 7.4 & 7.5 & 7.6 \\
\hline & \multirow{2}{*}{$\mathrm{L}$} & $A \cdot I$ & 14.3 & 15.1 & 17.5 & 18.6 \\
\hline & & $\mathrm{I} \cdot \mathrm{I}$ & 8.6 & 8.7 & 8.8 & 8.9 \\
\hline & \multirow{2}{*}{$\mathrm{SiL}$} & $A \cdot I$ & 16.1 & 17.0 & 19.6 & 20.8 \\
\hline & & $\mathrm{I} \cdot \mathrm{I}$ & 9.9 & 10.0 & 10.1 & 10.3 \\
\hline \multirow{6}{*}{ Jeju } & \multirow{2}{*}{ SL } & $A \cdot I$ & 10.5 & 11.3 & 16.1 & 16.2 \\
\hline & & $\mathrm{I} \cdot \mathrm{I}$ & 7.2 & 7.3 & 7.7 & 7.7 \\
\hline & \multirow{2}{*}{$\mathrm{L}$} & $A \cdot I$ & 12.5 & 13.5 & 19.3 & 19.5 \\
\hline & & $\mathrm{I} \cdot \mathrm{I}$ & 8.5 & 8.5 & 9.0 & 9.0 \\
\hline & \multirow{2}{*}{$\mathrm{SiL}$} & $A \cdot I$ & 14.1 & 15.2 & 21.7 & 21.8 \\
\hline & & $\mathrm{I} \cdot \mathrm{I}$ & 9.8 & 9.9 & 10.3 & 10.4 \\
\hline
\end{tabular}

\footnotetext{
${ }^{\dagger} \mathrm{A} \cdot \mathrm{I}=$ Amount of Irrigation $(\mathrm{mm}), \quad \mathrm{I} \cdot \mathrm{I}=$ Irrigation Interval (days)

${ }^{\dagger \dagger}$ Soil Texture: SL $=$ Sandy Loam, $\mathrm{L}=$ Loam, $\mathrm{SiL}=$ Silt Loam

†⿰† Growth Stage: G-1 = Growth Stage-1 (5/10 5/31), G-2 = Growth Stage-2 (6/1 6/30), G-3 = Growth Stage-3 (7/1 7/31), G-4 = Growth Stage-4 (8/1 8/20)
}

Table 6. Total amount of inigation water ofhe full inigation standard (FIS), deficit inigation standard (DIS) and partial root-zone drying imigation standard (PRDIS) for tomato in greenhouse.

\begin{tabular}{ccccccccccc}
\hline \hline Area & Suwon & Gangneung & Buyeo & Jecheon & Mokpo & Jeonju & Milyang & Yeongju & Jeju & Mean \\
\hline FIS & 387.7 & 545.3 & 377.8 & 363.4 & 409.4 & 389.4 & 389.5 & 399.7 & 380.6 & 404.8 \\
DIS & 280.7 & 271.4 & 268.9 & 256.6 & 337.0 & 277.7 & 284.3 & 296.6 & 308.2 & 286.8 \\
PRDIS & 183.2 & 181.2 & 179.7 & 176.5 & 223.9 & 182.4 & 183.9 & 189.1 & 187.0 & 187.4 \\
\hline
\end{tabular}

시설재배 토마토는 5월 5일 정식을 재배기준으로 삼아 지역별 및 시기별 잠재증발산량, 토성별 유효수분 보유량, 토마토의 생육시기별 작물계수, 토양수분 계수 및 $\mathrm{P}$ 값의 결 과를 이용하여, 식 (8)과 식 (9)에 근거하여 최종적으로 산 출한 시설재배 토마토의 물 절약형 관개기준 (관개간격 및 1 회 관개량)인 부족관개 기준 (DIS)은 Table 4, 그리고 부분 건조 관개기준 (PRDIS)은 Table 5 와 같다. 물 절약형 관개는 물리적 증수 보다는 물 생산성 (WP: Water Productivity) 및 물 이용효율 (WUE: Water Use Efficiency)의 증진에 그
목적이 있다. 그 중 부족관개 (DI)는 물 절약과 물 생산성 (WP) 증가에, 부분건조 관개 (PRDI)는 물 생산성 (WP) 및 물 이용효율 (WUE) 증진과 물리적 증수 (DI 대비)에 그 목 적이 있는 관개방법이다. 또한, 부족관개 기준 (DIS)은 주어 진 토양에서 생육시기별 1회 관개 량 $(\mathrm{A} \cdot \mathrm{I})$ 은 동일하며, 관 개간격 $(\mathrm{I} \cdot \mathrm{I})$ 이 차이 난다. 한편 부분건조 관개 기준 (PRDIS) 은 주어진 토양에서 생육시기별 1 회 관개 량 $(\mathrm{A} \cdot \mathrm{I})$ 은 차이가 크며, 관개간격 $(\mathrm{I} \cdot \mathrm{I})$ 은 차이가 작으나, 토성 간에는 그 차이 가 크다. 
시설재배 토마토의 3 종류 관개기준에 따라 토마토 전 생 육기간 동안 필요한 총 관개량 (Table 6)은 기존 물관리 지 침서 (FSI: 완전관개기준)의 경우 (제천) $363.4 \sim$ (강릉) $545.5 \mathrm{~mm}$ 범위의 평균 $404.8 \mathrm{~mm}$ 이었다. 본 연구결과의 물 절약형 관개기준인 부족관개 기준 (DIS)의 경우 256.6 $337.0 \mathrm{~mm}$ 범위의 평균 $286.8 \mathrm{~mm}$ 로서 완전관개 기준 (FSI)의 $70.8 \%$ 수준이었으며, 부분건조 관개기준 (PRDIS) 의 경우 $176.5 \sim 223.9 \mathrm{~mm}$ 범위의 평균 $187.4 \mathrm{~mm}$ 로서 완 전관개 기준 (FSI)의 $46.3 \%$ 수준이었다. 따라서, 물 절약형 관개 기준에 의하면 토마토 재배에 있어 우리나라 지역 전 체 평균적으로 완전 관개 기준 (FIS) 대비 $29.2 \% \sim 53.7 \%$ 의 물 절약 효과가 있을 것으로 나타났다.

유의사항 고찰 상기한 3 종류의 관개 기준에 따라 총 관개량의 차이가 큰 이유는: 첫째, $\mathrm{p}$ 값 설정에 있어 관개시 점 기준이 FSI 경우는 작물이 항상 최대증발산량을 유지할 수 있는 토양수분 potential (10 15 kPa) 이었으며(Eom et al., 1999), 물 절약형 관개기준 (WSIS)의 경우는 최대증발 산량 $(\mathrm{MET})$ 의 함수로 증발산량이 감소하기 시작하는 임계 토양수분 조건에 근거하였기 때문으로 사료되며, 둘째, 관 개방법별 관개효율을 고려시 완전관개 기준 (FIS)은 관개효 율이 50 $80 \%$ 정도 되는 고랑관개 또는 Sprinkler 관개 및 전면 점적관개 등의 관개 방법을 기준하였고, 물 절약형 관개기준 (WSIS)의 경우는 관개효율 $100 \%$ 기준으로 산정한 결과로 판단된다. 따라서 물 절약형 관개기준 (WSIS)에 따 를 경우 반드시 점적관개 방법으로 하여야 하며, 전면관개 (DI 경우) 보다는 부분관개 (PRDI 경우) 방법을 이용하면 관 개 량을 절약하면서도 작물 수량 감소가 없는 물 관리 방식 임을 밝혀두는 바이다.

또한, 상기 관개기준에 따라 실제 관개량 (AAI: Actual Amount of Irrigation)은 관개방법별 관개효율 ( $\mathrm{IEi}$ : Irrigation Efficiency)을 고려한 식 (11)과 같이 산정하여 적 용하여야 한다.

$\mathrm{AAI}=[\mathrm{A} \cdot \mathrm{I}] / \mathrm{IEi}$

\section{Conclusion}

1. 우리나라 전국을 9 개 지역으로 구분하여 최근 30 년간의 시설재배 토마토 생육기간인 5 월 8월의 일평균 잠재증 발산량 (PETGHavg)은 $3.41 \mathrm{~mm} \mathrm{day}{ }^{-1}$ 이었다.

2. 시설재배 토마토의 9 개 지역별, 3 개 토성 및 10 개 순별, 총 270 경우의 재배여건에 적합한 물 절약형 관개기준 (적정 관개간격 및 1 회관개량)을 설정하였다.

3. 물 절약형 관개기준 (WSIS)인 부족관개기준 (DIS: Deficit Irrigation Standard) 및 부분건조 관개기준 (PRDIS: Partial Root-zoon Drying Irrigation Standard)에 의한
시설 재배 토마토의 전 생육기간 요구되는 총 관개량은 각각 286.8 및 $187.4 \mathrm{~mm}$ 이었다.

4. 부족 관개기준 (DIS) 및 부분건조 관개기준 (PRDIS)에 의하면, 최대 관개기준인 기존의 물 관리지침서 (FIS: Full Irrigation Standard) 대비 각각 $29.2 \%$ 및 $46.3 \%$ 의 물 절약 효과를 볼 수 있다.

\section{References}

Blaney, H.F. and W.D. Criddle. 1962. Determining consumptive use and irrigation water requirement. Agr. Res. Ser. USDA Tech. Ball. 1275:1-59.

Eom, K.C., D.S. Oh, K.C. Song, I.S. Jo, and D.W. Seo. 1999. Water management manual on upland field. National Academy of Agricultural Science. RDA. Vol. 65. (In Korean).

Eom, K.C., E.R. Son, and S.H. Yoo. 1983. Fertilizer response of chinese cabbage to soil water potential. Korean J. Soil Sci. \& Fert. 16:98-105.

Eom, K.C., K.C. Song, K.S. Ryu, Y.K. Sonn, and S.E. Lee. 1995. Model equations to estimate the soil water characteristics curve using scaling factor. Korean J. Soil Sci. \& Fert. 28:227-232.

Eom, K.C., P.K. Jung, M.H. Koh, S.H. Kim, S.Y. Yoo, S.H. Park, S.O. Hur, and S.K. Ha. 2010. Water Saving Irrigation Manual of Spring Chinese Cabbage. Korean J. Soil Sci. \& Fert. 43(6):812-822.

Eom, K.C., S.K. Ha, S.O. Hur, Y.S. Jung, and K.S Ryu. 2009. Soil water. Korean J. Soil Sci. \& Fert. 42 (extra):102-125

FAO. 1971. Irrigation practice and water management. Irrigation and drainage paper. pp. 13-54.

Im, J.N. 1987. Modeling of estimating soil moisture, evapotranspiration and yield of chinese cabbages from meteorological data at different growth stages. Seoul Nat'l Univ. pH. D thesis. pp. 27-34.

Im, J.N. and S.H. Yoo. 1988. Modeling of estimating soil moisture, evapotranspiration and yield of chinese cabbages from meteorological data at different growth stages. Korean J. Soil Sci. \& Fert. 21(4):386-408.

Jensen, M.E. and H.R. Heise. 1963. Estimating evaporation from solar radiation. J. Irrig. Drain. Div. Am. Soc. Cir. Eng. 89:15-41.

Jensen, M.E. and H.R. Heise. 1974. Consumptive use of water and irrigation water requirements. American Society of Civil Engineers.

KMA. 2008. Weather Forecast of Korea Meteorological Administration.

Klute, A. 1986. Water retention: laboratory methods, in methods of soil analysis. Madison. Wisconsin. USA. pp. 635-662.

Penman, H.L. 1948. Natural evaporation from open water, bare soil and grass. Proc. Roy. Soc. London. A193:120-146.

Penman, H.L. 1956. Evaporation: An introductory survey. 
Netherlands J. Agric. Sci. 1:9-29, 87-97, 151-153. RDA. 1982-1996. NAAS Research report (In Korean).

Sepaskhah, A. R. and S. H. Ahmadi. 2010. A review on partial root-zone drying irrigation. International Journal of Plant
Production. 4 (4) : 241-258.

Ward, A. and S. Trimble. 2004. Environmental hydrology. Lewis Publishers, USA. 465. 